\title{
Modal Noneism: Transworld Identity, Identification, and Individuation
}

\author{
Dr Francesco Berto \\ University of Aberdeen and University of Amsterdam
}

\begin{abstract}
Noneism a is form of Meinongianism, proposed by Richard Routley and developed and improved by Graham Priest in his widely discussed book Towards Non-Being. Priest's noneism is based upon the double move of (a) building a worlds semantics including impossible worlds, besides possible ones, and (b) admitting a new comprehension principle for objects, different from the ones proposed in other kinds of neo-Meinongian theories, such as Parsons' and Zalta's. The new principle has no restrictions on the sets of properties that can deliver objects, but parameterizes the having of properties by objects to worlds. Modality is therefore explicitly built in - so the approach can be conveniently labeled as "modal noneism". In this paper, I put modal noneism to work by testing it against classical issues in modal logic and semantics. It turns out that - perhaps surprisingly - the theory (1) performs well in problems of transworld identity, which are frequently considered to be the difficult ones in the literature; (2) faces a limitation, albeit not a severe one, when one comes to transworld individuation, which is often taken (especially after Kripke's notorious 'stipulation' solution) as an easy issue, if not a pseudo-problem; and (3) may stumble upon a real trouble when dealing with what I shall call 'extensionally indiscernible entities' - particular nonexistent objects modal noneism is committed to.
\end{abstract}

The road to Nothing is paved with good intensions.

John Bartlett, Familiar Quotations (slightly modified) 


\section{$1 \quad$ Inspecting Modal Noneism}

In his classic 1980 book Exploring Meinong's Jungle and Beyond, Richard Routley (later Sylvan) developed a kind of neo-Meinongian semantics and ontology he dubbed 'noneism'. In his Towards Non-Being, the champion of dialetheism Graham Priest has proposed a couple of interesting developments for Routley's theory. Priest's noneism is based upon a new comprehension principle for objects, different from the ones proposed in other kinds of neoMeinongian theories, such as Parsons [1980] and Zalta [1983]. A key move in the strategy, following suggestions by Daniel Nolan (Nolan [1998]) and Nick Griffin (Griffin [1998]), consists in having no restrictions on the (sets of) properties that can deliver objects, but in parameterizing the having of properties by objects to (both possible and impossible) worlds. Modality is therefore explicitly built in such a principle; because of this, the approach can be conveniently labeled as modal noneism.

Priest claims that "a number of the techniques developed in the book are relatively novel and untried (and) though I take up what seem to me to be many of the most important questions and objections, I am sure there are numerous others, probably even important others, that are not addressed." Priest [2005], p. x. This paper aims at showing how modal noneism escapes some possible (and also actual) objections, and at addressing what I think is a general problem of the approach.

Specifically, I am interested in checking how, when Meinongian themes are combined with a non-standard modal framework, the resulting noneist theory behaves with respect to typical issues in the metaphysics of modality, such as transworld identity and identification. The canonical entry on nonexistent objects of the Stanford Encyclopedia of Philosophy claims that modal noneism "raises difficult questions about cross-world identity." (Reicher [2004], 5.1). However, I shall show that - perhaps surprisingly - modal noneism (1) performs well in problems of transworld identity, that are often taken to be the hard ones; (2) encounters a limitation, but not a drastic one, when one comes to transworld individuation, which is usually considered, especially after Kripke's influential stance on it, as a pseudo-problem; and (3) may face a real trouble when dealing with the identity of what I shall call extensionally indiscernible entities - particular nonexistent objects modal noneism is committed to. Let us start by introducing the basics of modal noneism. 


\section{From Naïve Meinongianism to Modal Non- eism}

As is well known, Meinongians begin by distinguishing the Sein of objects their existential status - from their Sosein, their having - certain - features or properties (which ones? This is a key issue to be addressed later). And Meinongians claim that an object can have a set of features even if it doesn't exist. This is the so-called 'Principle of Independence'.

Secondly, this intuition has a beautifully simple formal treatment. Primitive quantifiers, say, $\Lambda$ and $\Sigma$ (to be read as 'for all' and 'for some') are taken as existentially neutral: one can quantify over, and talk in general of, nonexistents. Existence is expressed by a perfectly normal first-order predicate say, 'E!' - employed to provide explicit existential commitment and to define the existentially loaded quantifiers. 'All existing things are such that...' is:

(1) $\forall x \alpha(x)={ }_{d f} \Lambda x(E ! x \rightarrow \alpha(x))$

and 'There exists something such that...' is:

(2) $\exists x \alpha(x)=_{d f} \Sigma x(E ! x \wedge \alpha(x))$

Meinong claimed "There are objects of which it is true that there are no such objects." Meinong [1969], p. 490. But this is not a flat contradiction at all, when one has distinguished the two couples of quantifiers ${ }^{1}$ - on the contrary, it is mirrored in everyday talk:

(3) There is something which has been sought by many, namely the site of Atlantis, but it does not exist. (Wolterstorff [1961])

(4) I thought of something I would like to give you as a Christmas gift, but I couldn't buy it for you because it doesn't exist. (Priest [2005])

In Meinongian logics, contra the Quinean motto, to be (to exist) is not to be the value of a (bound) variable. (See Parsons [1980], Zalta [1983], Jacquette [1996].) Naïve Meinongianism endorses what we may call, following Parsons [1979a], Parsons [1980] and by analogy with naive set theory, an Unrestricted Comprehension Principle for objects:

(UCP) For any condition $\alpha(x)$ with free variable $x$, some object satisfies $\alpha(x)$.

\footnotetext{
${ }^{1}$ In fact, to speak of 'two couples of quantifiers', as many do when exposing Meinongianism, is a bit misleading: the existentially loaded couple is explained away by defining it via the primitive neutral quantifiers and the existence predicate.
} 
This gives us the schema:

(5) $\Sigma x \alpha(x)$

for every $\alpha(x){ }^{2}$ The intuition is that we specify an object via a given set of properties, such as is a winged horse, is captured by Bellerophon, climbs Mount Olympus in search of the Chimera. . . Suppose $\alpha(x)$ is the conjunction of the relevant predicates. Then, according to the UCP, an object is described by $\alpha(x)$. If you call the object so described 'Pegasus', $p$, then Pegasus has the pertinent set of properties: $\alpha(p)$.

The UCP is supposed to hold broadly a priori: it explains how we can know many things about nonexistent objects: "we know that objects characterized in certain ways have (such and such) properties, precisely because they are characterized in that way." (Priest [2005], p. viii). Nonexistent objects must have the properties they are characterized as having, and this is why we know what we are talking about when we talk about them - $a$ priori, broadly speaking, i.e., via a kind of knowledge that doesn't require causal connections which are not available with nonexistents. ${ }^{3}$

Nonetheless, as is well known, the UCP in its naïve form leads to unacceptable consequences and is doomed to go down in flames. Two famous objections by Russell (Russell [1905b], Russell [1905a]) have been taken as a definitive refutation of Meinongianism tout-court, namely (1) the objection from inconsistency, and (2) the claim that the UCP allows us to prove the existence of whatever we want. Let us have a look at them.

Firstly, if one takes into account inconsistent characterizations, the UCP forces us to admit not only possible objects, but also impossible ones, in the strict sense of objects that violate the Law of Non-Contradiction. Quine's (Quine [1948]) (in)famous example is 'the round square cupola of Berkeley College'. ${ }^{4}$

\footnotetext{
${ }^{2}$ Russell's criticisms of Meinong (Russell [1905b], Russell [1905a]) addressed definite descriptions, so the UCP might accordingly be reformulated as:

(UCP)Any definite description $\iota x \alpha(x)$ designates an object satisfying the description.

This gives us the schema:

(5b) $\alpha(\iota x \alpha(x))$

${ }^{3}$ As an anonymous referee has pointed out to me, stress on aprioricity may be unappropriate when addressing Priest's variant of Meinongianism, given that Priest has a broadly Quinean epistemology which might reject an absolute distinction between a priori and $a$ posteriori. I think that a minimal characterization of aprioricity as knowledge without causal acquaintance may be acceptable to Priest as well - and this is all I need in the following.

${ }^{4} \mathrm{~A}$ dual difficulty comes from the incompleteness of fictional objects, which seems to
} 
Secondly, if the UCP held generally for any condition we could run an 'ontological argument' to prove the existence of anything we like. For instance, one may consider the following set of properties:

$$
\text { \{goldenness, mountainhood, existence\} }
$$

that is, one may pick the condition $\alpha(x)=x$ is golden and $x$ is a mountain and $x$ exists. Now existence is a perfectly normal first-order property for Meinongians, so the UCP would give us a priori an existent golden mountain.

As a result, it seems that we have to restrict the class of conditions $\alpha(x)$ that may be used to deliver objects; so Meinongians face what we may call a problem of plenitude for nonexistent objects: find a principle that grants as many objects as possible, but without the unwelcome consequences of the naïve theory. Meinongians have been struggling with this, and different kinds of Meinongianism are delivered by the different basic concepts they introduce in their restricted or modified comprehension principles. Parsons [1980] and Jacquette [1996] introduce a subclass of predicates (called assumptible, characterizing or, more often, nuclear - the terminology is due to J.N. Findlay [1963]), to be used in order to deliver objects. ${ }^{5}$ The Comprehension Principle is now restricted to nuclearity:

(NCP) For any condition $\alpha(x)$ on nuclear properties with free variable $x$, some object satisfies $\alpha(x)$.

The 'dual copula' Meinongian approach by Rapaport [1978], Zalta [1983], and others, is based upon distinguishing two modes of predication: standard exemplification and encoding (to stick to Zalta's terminology). The Dual Copula Characterization Principle is formulated with respect to encoding:

(DCP) For any condition $\alpha(x)$ with free variable $x$, some object encodes $\alpha(x)$.

Now, Priest claims he can do better. The two Russellian problems are addressed more efficiently by modal noneism via the double move of (1) building a world semantics which includes (logically) impossible worlds, besides

threaten the Law of Excluded Middle, and/or Bivalence. I will not take into account here the issue whether incomplete objects are impossible or not, even though endorsement of De Morgan laws suggests that they might be.

${ }^{5}$ Here are a few examples, taken from Parsons [1980]; for nuclear predicates: "is blue", "is tall", "kicked Socrates", "was kicked by Socrates", "kicked somebody", "is golden", "is a mountain"... Extranuclear predicates come in various kinds - Ontological: "exists", "is mythical", "is fictional"...Modal: "is possible", "is impossible"... Intentional: "is thought about by Meinong", "is worshipped by someone"... Technical: "is complete", "is consistent"... The intuition is that nuclear properties characterize the very nature of the objects, whereas extranuclear properties somehow supervene on nuclear ones.

Australasian Journal of Logic (11:2) 2014, Article no. 1 
possible ones, and (2) admitting a comprehension principle for objects in unrestricted, but qualified form.

Impossible worlds, defined as worlds where the laws of logic are different, ${ }^{6}$ are a well known, albeit controversial, subject of logical and philosophical investigation. They are nowadays proposed by various authors as a natural extension of possible worlds theories, having useful applications in the study of the notions of propositional content, intentional state, belief management, etc. ${ }^{7}$ By admitting impossible worlds, we can account for inconsistent objects, such as Quine's round square cupola, that is, an object which, given that if something is a square then that thing is not round, is round and not round, $R x \wedge \neg R x$. We simply admit inconsistent worlds that realize contradictions. Notice that we do not need to admit true contradictions, or even possibly true ones, against the LNC (for the non-factive "at world w" does not allow us to move from something's being round and not round at impossible world $w$ to its being round and not round simpliciter): despite Priest's being a well known supporter of true contradictions, modal noneism can retain some neutrality on this issue.

It is move (2) that interests us more. This consists in admitting a(n unrestricted but) Qualified Comprehension Principle for objects, by parameterizing it to worlds: given any condition $\alpha(x)$, some object is described by it. However, it has its characterizing properties, not necessarily at this world, but at others - at the worlds that make the characterization true:

(QCP) For any condition $\alpha(x)$ with free variable $x$, some object satisfies $\alpha(x)$ at some world. (see Priest [2005], pp. viii and 84)

After all, nonexistent objects are, typically, the target of intentional states and cognitive representations; and a uniform account of intentionality was one of the main motivations for Meinong's introduction of nonexistent objects. Hence comes Priest's justification of the move:

Cognitive agents represent the world to themselves in certain ways. These may not, in fact, be accurate representations of this

\footnotetext{
${ }^{6}$ This definition is logic-relative: given some logic $\mathrm{L}$, an impossible world is one in which the set of truths is not one that holds in any acceptable interpretation of L. A more restrictive definition claims that impossible worlds are worlds where the set of things that hold is not the set of things that hold in any classical interpretation. A classical logician can consider a world where the Law of Excluded Middle fails as a logically impossible world, since she takes classical logic as the correct logic. A still more specific definition claims that an impossible world is a world where some contradictions are true, that is, where sentences of the form $\alpha$ and $\neg \alpha$ hold, against the Law of Non-Contradiction.

${ }^{7}$ For a general introduction, see e.g. Beall and van Fraassen [2003]. See also Pasniczek [1998], and the monographic no. 38(1997) of the Notre Dame Journal of Formal Logic, entirely devoted to impossible worlds.
} 
world, but they may, none the less, be accurate representations of a different world. For example, if I imagine Sherlock Holmes, I represent the situation much as Victorian London (so, in particular, for example, there are no aeroplanes); but where there is a detective that lives in Baker St, and so on. The way I represent the world to be is not an accurate representation of our world, but our world could have been like that; there is a world that is like that. (Priest [2005], p. 84)

To be more precise, there are many such worlds, since representations are incomplete with respect to many details. Objects picked by a description, therefore, may always satisfy the relevant condition, $\alpha(x)$. According to Priest, we don't need to isolate a subset of 'nuclear' or characterizing properties. Also the set \{goldenness, mountainhood, existence\} works fine now: we need not assume that an object so characterized, that is, an existent golden mountain, has its characterizing properties at the actual world. As far as we know, no golden mountain inhabits the actual world, but golden mountains are available at the worlds at which the stories we can tell on existent golden mountains hold.

We can stick to the idea that objects also have properties entailed by those they are explicitly characterized as having, given some suitable notion of entailment. In particular, since in Routley's noneism to exist is to have causal properties, and/or to be located in space and time, some properties or relations involving causal features can be taken as existence-entailing in one or more arguments. The idea can be found in Linsky and Zalta [1994] in point of fact, they talk of concreteness-entailing properties, but providing a rough-and-ready translation from their modal theory to modal noneism is not too complicated. For instance, if $\mathrm{x}$ kisses $\mathrm{y}$, then both $\mathrm{x}$ and $\mathrm{y}$ must exist, and if $\mathrm{x}$ thinks about $\mathrm{y}, \mathrm{x}$ must exist although $\mathrm{y}$ need not (at least at possible worlds: more on this in the next paragraph). This accounts for the intuitive idea that Sherlock Holmes, being a nonexistent object at this world, cannot actually kiss anyone here, nor can he entertain any thought here, although he can be thought of (by Doyle, or by any reader of the Doyle stories). However, if some Doyle novel features Holmes kissing Watson, then Holmes does kiss Watson at the worlds at which the characterization is true and, at those worlds (or at least, at the possible ones among them), Holmes does exist.

Enough for the basics of the theory. Before we come to the substantive part of this paper, though, I need to introduce some formal machinery that will later help to state and discuss issues.

Australasian Journal of Logic (11:2) 2014, Article no. 1 


\section{Formalities}

The following formal semantics comes basically from Priest's account (Priest [2005]), but with a few adjustments and, above all, simplifications. Priest aims at providing a treatment of intentional contexts, taking into account the typical intentional failures of substitutivity, logical omniscience, etc. His book also aims at a broad account of the semantics of definite and indefinite descriptions, and of various other subjects. Only a subset of the items targeted is relevant here, and the formal semantics is simplified accordingly.

So take the usual first-order language with a set of individual constants, n-place predicates (with a distinguished one-place predicate, $E$ !), individual variables, the standard connectives $\neg, \wedge, \vee, \rightarrow$, the two Meinongian quantifiers, $\Lambda$ and $\Sigma$, box and diamond, $\square, \diamond$, and the usual rules for wellformedness. We also have a sentential operator (c) for conceivability: if $\alpha$ is any well-formed formula, 'C $\alpha$ ' is a well-formed formula, to be read: 'It is conceived that $\alpha$ '. ${ }^{8}$ An interpretation of the language is an octuple $<P, I, E$, @ , D, R, $C, v>$, where $P$ is the set of possible worlds, and $I$ and $E$ are two sets of impossible worlds of different kinds. I dub $I$ the set of the intensionally impossible worlds (in a sense to be explored soon) and $E$ the set of extensionally impossible worlds (ditto). $P, I$ and $E$ are disjoint and $W=P \cup I \cup E$ is the totality of worlds. @ $\in P$ is the distinguished actual world. This would not be needed if all we wanted from the semantics were accounts of validity and logical consequence; but @ is to do other, quite important jobs, as we shall see. $D$ is a non-empty set of objects, $R$ is a ternary relation on $P \cup I$ (an optional element of the structure, as we will also see), and $C$ is a binary relation on the whole set $W$.

We have constant domain worlds semantics: each world has the same domain, namely D. This is quite natural for Meinongians. People assume variable domains in ordinary Kripke semantics to account for the idea that different things may exist at different worlds. But in a modal noneist framework the unique domain is simply the totality of objects: that some object $o$ exists at world $w_{1}$, but not at world $w_{2}$, is accounted for by having $o$ satisfy the existence predicate $E$ ! at $w_{1}$ and not at $w_{2}$, and all the epicycles of

\footnotetext{
${ }^{8}$ Priest phrases his intentional operator $(\mathrm{s})$ as ' $\alpha$ is conceived (represented, imagined, etc.) by cognitive agent $a$ ', therefore endorsing a multi-modal approach; but the agent is mostly carried around as a parameter and doesn't do much work - especially, not much work relevant to the questions addressed here. As an anonymous referee has suggested, it is worth stressing that 'conceivability' is not interpreted throughout this paper as the somewhat technical notion philosophers have started to use when, especially after Chalmers' works in the philosophy of mind, they have begun to debate on whether conceivability is a secure guide to metaphysical possibility.
} 
variable domain modal semantics are left behind: simplex sigillum veri.

Finally, $v$ is the interpretation function assigning denotations to the nonlogical symbols as follows:

- If $c$ is an individual constant, then $v(c) \in D$;

- If $P$ is an n-place predicate and $w \in W$, then $v(P, w)$ is a pair < $v+(P, w), v-(P, w)>$, with $v+(P, w) \subseteq D^{n}, v-(P, w) \subseteq D^{n}$.

If $P$ is an n-place predicate, $v$ assigns to it an extension $v+(P, w)$ and an anti-extension $v-(P, w)$ relative to worlds. Intuitively, the extension of $P$ at $w$ is the set of $n$-tuples of which $P$ is true there, and the anti-extension is the set of $n$-tuples of which it is false. For possible worlds, we require that the two be exclusive and exhaustive for any $P$ - let us call this the Classicality Condition:

(CC) If $w \in P$, then $v+(P, w) \cap v-(P, w)=\emptyset$

$v+(P, w) \cup v-(P, w)=D^{n}$

This reflects the idea that possible worlds must be maximally consistent: for any predicate $P$, if $w$ is a possible world, $P$ is either true or false of the relevant object(s) at $w$, but not both. Nevertheless, truth and falsity conditions are spelt separately (in a way familiar from various kinds of nonbivalent semantics), for things may go differently at impossible worlds.

In order to evaluate quantified sentences we need assignments of denotations to the variables, and a parameterization of the interpretation function, the usual way: if $a$ is an assignment (a map from the variables to D), then $v_{a}$ is the suitably parameterized interpretation, which goes as follows:

- If $c$ is an individual constant, then $v_{a}(c)=v(c)$;

If $x$ is a variable, then $v_{a}(x)=a(x)$.

Next, we read " $w \models_{a}^{+} \alpha$ " as " $\alpha$ is true at world $w$ with respect to assignment $a$ ", and " $w \models_{a}^{-} \alpha$ " as " $\alpha$ is false at world $w$ with respect to assignment $a$ " (I will sometimes omit the subscript when we are dealing with closed formulas, for which different assignments, as usual, make no difference). Then we have, for atomic formulas:

- $w=_{a}^{+} P t_{1} \ldots t_{n}$ iff $<v_{a}\left(t_{1}\right), \ldots, v_{a}\left(t_{n}\right)>\in v+(P, w)$ $w=_{a}^{-} P t_{1} \ldots t_{n}$ iff $<v_{a}\left(t_{1}\right), \ldots, v_{a}\left(t_{n}\right)>\in v-(P, w)$

For negation:

- $w \models_{a}^{+} \neg \alpha$ iff $w \models_{a}^{-} \alpha$ $w=_{a}^{-} \neg \alpha$ iff $w=_{a}^{+} \alpha$

Australasian Journal of Logic (11:2) 2014, Article no. 1 
Since extensions and anti-extensions are exclusive and exhaustive at possible worlds, if $w \in P$ we have that $w \models_{a}^{+} \neg \alpha$ iff it is not the case that $w \models{ }_{a}^{+} \alpha$; so thanks to the $\mathrm{CC}$ at possible worlds negation works "homophonically", the classical way. And since @ $\in P$, that is, the actual world is a possible one, there are no truth value gluts or gaps at it: truth simpliciter, truth at @, behaves in an orthodox way with respect to negation.

Conjunction and disjunction work as follows: for all $w \in P \cup I$,

- $w \models_{a}^{+} \alpha \wedge \beta$ iff $w \models_{a}^{+} \alpha$ and $w \models_{a}^{+} \beta$

$w \models{ }_{a}^{-} \alpha \wedge \beta$ iff $w=_{a}^{-} \alpha$ or $w \models_{a}^{-} \beta$

- $w \models_{a}^{+} \alpha \vee \beta$ iff $w \models_{a}^{+} \alpha$ or $w \models_{a}^{+} \beta$

$w \models_{a}^{-} \alpha \vee \beta$ iff $w \models_{a}^{-} \alpha$ and $w \models_{a}^{-} \beta$

This means that conjunction and disjunction behave in an orthodox fashion (except, of course, for the fact that they are given truth and falsity conditions separately) at possible worlds in $P$, and also at the intensionally impossible worlds in $I$. Instead, they behave anarchically at extensionall impossible worlds, that is, members of $E$ : here the truth values of conjunctions and disjunctions are not determined recursively. The interpretation function $v$ treats them as atomic, assigning extensions and anti-extensions directly, following the idea of (im)possible worlds models introduced by Rantala [1982] in order to provide a semantics for intentional operators making logical omniscience fail. So at points in $E$ the truth values of conjunctions and disjunctions are not assigned recursively, but directly determined by $v$. Before explaining why things go this way, a little more needs to be said on the rest of the logical vocabulary. The conditional is a tricky issue, and many different treatments are certainly possible. One can have the standard material conditional, say, "つ", by defining:

$$
\alpha \supset \beta={ }_{d f} \neg \alpha \vee \beta
$$

As for a "vertebrate" conditional, say, $\rightarrow$, at possible worlds we can have it work as a standard strict conditional: if $w \in P$,

- $w \models_{a}^{+} \alpha \rightarrow \beta$ iff for all worlds $w_{1}\left(\right.$ if $w_{1} \models_{a}^{+} \alpha$ then $w_{1} \models_{a}^{+} \beta$ )

- $w \models_{a}^{-} \alpha \rightarrow \beta$ iff for some $w_{1}\left(w_{1} \models_{a}^{+} \alpha\right.$ and $\left.w_{1} \models_{a}^{-} \beta\right)$

As for impossible worlds, one natural option is to adopt the RoutleyMeyer semantics for relevant logics with the ternary accessibility relation $R$ on worlds. Truth conditions can be given as follows: if $w \in I$, 
$(\mathbf{R M}) w \models_{a}^{+} \alpha \rightarrow \beta$ iff for all worlds $w_{1}, w_{2}$ such that $R w w_{1} w_{2}$ (if $w_{1} \models_{a}^{+} \alpha$, then $\left.w_{2}={ }_{a}^{+} \beta\right) .{ }^{9}$

Falsity conditions are more complicated, but we can skip this issue; the conditional can be treated more uniformly: we can have a RM-treatment hold for $P$-worlds and $I$-worlds if we make the following further assumption, usually called Normality Condition:

(NC) If $w \in P$, then $R w w_{1} w_{2}$ iff $w_{1}=w_{2}$.

With the help of NC, the relevant conditional behaves as a strict one at all possible worlds. A simpler option is to have it work as a strict conditional at possible worlds, and to make conditional formulas $\alpha \rightarrow \beta$ behave anarchically at impossible ones. Since impossible worlds are worlds where the laws of logic are different, and conditionals are used to express laws of logic, conditionals $\alpha \rightarrow \beta$ may take on any sort of value at impossible worlds: their truth values are not determined recursively, and the interpretation function $v$ treats conditionals as atomic, assigning extensions and anti-extensions directly, as it happened to conjunctions and disjunctions at $E$-impossible worlds. ${ }^{10}$ As for the modal operators, if $w$ is a possible world:

- $w=_{a}^{+} \square \alpha$ iff for all $w_{1} \in P, w_{1}=_{a}^{+} \alpha$ $w=_{a}^{-} \square \alpha$ iff for some $w_{1} \in P, w_{1} \models_{a}^{-} \alpha$

- $w=_{a}^{+} \diamond \alpha$ iff for some $w_{1} \in P, w_{1} \models_{a}^{+} \alpha$ $w=_{a}^{-} \diamond \alpha$ iff for all $w_{1} \in P, w_{1}=_{a}^{-} \alpha$

The clauses for the modal operators have world quantifiers ranging only over possible worlds: after all, (unrestricted) necessity is truth at all possible worlds, and (unrestricted) possibility is truth at some possible worlds.

\footnotetext{
${ }^{9}$ This clause is tailor-made to avoid validating the 'fallacy of relevance' $\alpha \rightarrow(\beta \rightarrow \beta)$, in which antecedent and consequent may share no propositional parameter. Non-normal worlds were introduced in relevant logics exactly to do this job: a counterexample to the fallacy is provided by an impossible world $w$ such that for some (possible or impossible) worlds $w_{1}$ and $w_{2}$, such that $R w w_{1} w_{2}, \beta$ holds at $w_{1}$ and fails at $w_{2}$. How do we read ' $R w w_{1} w_{2}$ ', though? Here is a little bit of help from the literature: "In interpreting $R x y z$ perhaps the best reading is to say that the combination of the pieces of information $x$ and $y$ (not necessarily the union) is a piece of information in $z(\ldots)$. On this reading Rxyz can be regarded as saying that $x$ and $y$ are compatible according to $z$, or some such thing." Dunn [1986], p. 200. "An entailment $(\alpha \rightarrow \beta)$ is true at some world if this world sees an accessibility between two other worlds such that if $(\alpha)$ is true at the first of these worlds $(\beta)$ is true at the other." Bremer [2005], p. 67

${ }^{10}$ This solution was first introduced, as far as I know, in Routley and Loparic [1978], and is advertised in Priest [2001], 165-7.
}

Australasian Journal of Logic (11:2) 2014, Article no. 1 
At impossible worlds of the $I$-kind and of the $E$-kind, $v$ can assign truth values directly and non-recursively to formulas of the form $\square \alpha$ and $\diamond \alpha$, treating them as atomic as well. As for the quantifiers, they also behave in an orthodox fashion at worlds in $P$, and $I$, and anarchically at extensionally impossible worlds $E$. At all $w \in P \cup I$, then:

- $w \models_{a}^{+} \Lambda x \alpha$ iff for all $d \in D, w \models_{a(x / d)}^{+} \alpha$

$w \models-{ }_{a}^{-} \Lambda x \alpha$ iff for some $d \in D, w \models_{a(x / d)}^{-} \alpha$

- $w \models_{a}^{+} \Sigma x \alpha$ iff for some $d \in D, w \models_{a(x / d)}^{+} \alpha$

$w \models{ }_{a}^{-} \Lambda x \alpha$ iff for all $d \in D, w \models{ }_{a(x / d)}^{-} \alpha$

where " $a(x / d)$ " denotes the assignment which is the same as a, except that it assigns to $x$ the value $d$. As we saw above, existential commitment is supplied via a distinguished existence predicate, E!, to be used in the definition of the existentially loaded quantifiers. Also the existence-entailing features of some predicates can be accounted for by adding some formal constraints. As advertised there, I will assume that, if an $n$-place predicate $P$ is existence-entailing in its $i$ th place, it is such at all possible worlds:

- If $w \in P$, then if $\left\langle d_{1}, \ldots, d_{i}, \ldots, d_{n}>\in v+(P, w)\right.$, then $d_{i} \in v+$ $(E !, w)$.

Priest [2005], p. 60 does not take a stand on this; but it seems to me that existence-entailments may be regarded as something similar to a kind of meaning postulates, fixing the semantics of some predicates and, in particular, their internal connections to the predicate "exists". Meaning postulates can be taken as metaphysically necessary truths, holding at all metaphysically possible worlds (therefore, at all possible worlds simpliciter, if we make the simplifying assumption that metaphysical necessity is coextensive with logical necessity). So if Santa Claus thinks about Pegasus at $w$, then Santa Claus exists at $w$ though Pegasus need not; if Holmes kicks Moriarty at $w$, then both exist at $w$; and this holds whenever $w$ is a possible world. What happens at impossible worlds, of course, is another story; nonexistent things, for instance, may think or kick at some impossible world.

Finally, worlds are allowed to access $E$-impossible worlds when the truth conditions for the conceivability operator, (c), are at issue. If $w$ is a possible world:

- $w \models_{a}^{+}$(C) $\alpha$ iff for all $w_{1} \in W$ such that $w C w_{1}, w_{1} \models_{a}^{+} \alpha$

- $w \models_{a}^{-}$(C) $\alpha$ iff for some $w_{1} \in W$ such that $w C w_{1}, w_{1} \models_{a}^{-} \alpha$ 
These are the key clauses, and their intuitive explanation goes as follows. The semantics of the conceivability operator is just a restatement of the usual binary accessibility semantics for modal operators of ordinary modal logics. The idea is that $w C w_{1}$, that is, there is a conceivability accessibility ( $C$-accessibility) from $w$ to $w_{1}$, if and only if, at $w_{1}$, things are as they are conceived to be at $w$; or, equivalently: $w_{1}$ is $C$-accessible from $w$, just in case $w_{1}$ realizes the way things are characterized, or described - that is, conceived - to be at $w$. For instance, take the worst nightmares one may have (at @); then a world $w$ such that @ $C w$ is a nasty world at which those worst nightmares come true.

Now the reason why any impossible world, however logically anarchic, is accessible when evaluating formulas of the form ' $(C)$ ', is precisely that we can form inconsistent conditions more or less of any kind: $\alpha(x)$ may be ' $x$ is a round square', ' $x$ is round and not round', ' $x$ is red or blue but it is not the case that $x$ is red and it is not the case that $x$ is blue', etc. We may conceive (imagine, think of, tell stories about, etc.) objects having any (set of) properties, however extravagant. And our QCP tells us that for any condition $\alpha(x)$, there will be worlds at which some object satisfies $\alpha(x)$ (this is why we ultimately need such anarchic guys as impossible worlds).

Before I say something more on the sub-distinction between E-impossible worlds and I-impossible worlds, we need a definition of logical validity and logical consequence. It turns out that logical consequence is characterized in a very conservative and straightforward way - in fact, the usual way for modal logics with a distinguished base world: if $\mathrm{S}$ is a set of formulas,

$\mathrm{S} \models \alpha$ iff for every interpretation $\langle P, I, E, @, D, R, C, v\rangle$, and assignment $a$, if $@=_{a}^{+} \beta$ for all $\beta \in S$, then $@ \models_{a}^{+} \alpha$

For logical validity, we have just that $\models \alpha$ is $\emptyset \models \alpha$. So logical consequence is truth preservation at the base world, @, in all interpretations, and logical validity is truth at @ in all interpretations. In fact, one may also define logical consequence as truth preservation at all possible worlds in all interpretations: the semantics sketched contains nothing to differentiate @ from any other world $w$ in this respect, insofar as $w \in P$, that is, $w$ is possible (we are into what follows logically from what, therefore, in what follows from what at the worlds where logic is not different). As for the distinction between $I$-impossible worlds and $E$-impossible worlds: ${ }^{11}$ it is motivated by the will to

\footnotetext{
${ }^{11}$ Priest calls 'impossible worlds' what I have baptized as $I$-impossible worlds, and calls 'open worlds' what I have baptized as E-impossible worlds, meaning that the latter are not closed under logical entailment. However, given our definition of impossible world above, Priest's open worlds are obviously just impossible worlds of a certain (particularly anarchic) kind.
}

Australasian Journal of Logic (11:2) 2014, Article no. 1 
reconcile two opposite strands in the recent theorizing on impossible worlds two strands that reflect a certain ambiguity in the notion of impossible world itself.

(a) On the one hand, if one takes "impossible worlds" to mean "worlds where the laws of logic are different", as advertised above, then it is reasonable to assume that only the intensional conditional, and the box and diamond, behave in a non-standard fashion at them:

The truth conditions for conjunction, disjunction and the quantifiers remain the same at all worlds. Such operators have nothing to do with expressing laws of logic. The modal operators are clearly different, since their behaviour does concern the laws of logic, and what is logically possible or necessary at an impossible world may vary from what is actually so. (Priest [2005], p. 18)

If we followed this thread of thought, we would have to countenance in our semantic structure only $I$-impossible worlds. Such semantics would impose some structure to impossible worlds: conjunction, disjunction, and the quantifiers behave wisely at them, and the Routley-Meyer semantics for the conditional (admittedly, with the help of a few ad hoc clauses) refutes just the paradoxes of the conditional, but saves many ordinary inferences involving conditionals.

However some authors, e.g. Nolan [1997], favour an unrestricted comprehension principle for impossible worlds: for anything that cannot possibly be the case, there is an impossible world at which that thing is the case: there must be an impossible world for every way the world could not be. This route, which takes impossible worlds as pretty anarchic, is followed also by Vander Laan [1997] and Zalta [1997]: there are impossible worlds at which conjunctions, disjunctions, etc., can behave as atomic formulas, so that $\alpha \wedge \beta$ can be true even though $\alpha$ or $\beta$ are not true, etc.

Furthermore, given our unrestricted (albeit Qualified) Comprehension Principle for objects, we want to have worlds that realize the way things are conceived to be for any conception, however weird. In particular, for any, however minimal, logical restriction, one may conceive of objects that violate that restriction (non-adjunctive impossible objects, nonprime impossible objects, and so on). This is why in the semantic clauses for the evaluation of formulas prefixed with our conceiving operator (c), worlds are allowed to access impossible worlds of any kind.

How does the QCP square with all this? In naïve Meinongianism any condition characterized some object, but with no proviso on worlds at which the object had the relevant properties. In particular, for any condition $\alpha(x)$, calling $o$ an object characterized by the condition, we could have (using our 
newly introduced notation) @ $\models^{+} \alpha(o)$, and therefore, $@ \models^{+} \Sigma x \alpha(x)$. In our modally qualified framework, if an object $o$ is conceived as characterized by $\alpha(x)$, then we have that $@=^{+}(C) \alpha(o)$. Given the semantics of the conceivability operator, this entails only that, for all worlds $w$ that realize the way things are conceived as being at @, that is, for all w such that @ $C w$, $w \models^{+} \alpha(o)$ (and therefore, $w \models^{+} \Sigma x \alpha(x)$ ). As prescribed by the QCP, objects do have the features they are conceived-at-@ as having, but not at @: they have them only at the $C$-accessible worlds $w$ (which may be possible or impossible ones) that realize such conception. Sherlock Holmes is conceived-at-@, by Doyle and by the Sherlock Holmes fans and Doyle readers, as being a detective and (let us assume) kicking Moriarty. He does not have these properties at @, though - in particular, because being a detective and kicking someone appear to be existence-entailing properties, whereas, at @, Holmes does not exist. He has them, though, at the worlds that realize the relevant conception.

We now have all the formal machinery we need, and we can move on to the substantive issues.

\section{Transworld Identity is Not a Problem}

As hinted at above, the Stanford Encyclopedia entry on nonexistent objects ascribes to modal noneism difficulties with handling 'cross-world identity'. But what is meant here with 'cross-world identity'? Those familiar with the problems of transworld identity and identification in modal logic and metaphysics know that frequent misunderstandings have saddened the literature, mainly because the relevant notions and the problems at stake have not been spelled out carefully. So let us begin by giving a precise formulation.

The 'problem of transworld identity', correctly understood, is not an epistemic problem but a metaphysical one. It has to do with the conditions under which an object relating to some world $w_{1}$ in some way is the same as an object relating to some distinct world $w_{2}$ in the same way. The transworld identity thesis can be formulated in neutral terms as follows:

(TI) Some individual, $i$, is such that, for some worlds $w_{1}$ and $w_{2}, w_{1} \neq w_{2}$ and $i$ is at $w_{1}$ and $i$ is at $w_{2}$.

Does modal noneism have troubles with this? The key issue is what 'is at' means in TI. If by 'is at' one means 'is a part of' in the sense of 'part of' captured by some standard mereological theory, TI gets rejected by a modal realist of the Lewisian kind, because individuals according to Lewis are notoriously world-bound: no individual is (wholly) part of more than one Lewisian 
world. But also ersatz modal realists like Stalnaker or Plantinga may reject TI in this interpretation, although for a different reason: ersatz worlds are not maximal mereological sums of spatiotemporally related individuals. If, on the other hand, one substitutes 'individual' with the more generic 'worldconstituent', some ersatzers can accept TI because, on some accounts, ersatz worlds do have, as it were, 'overlapping' constituents. If worlds are abstract set-theoretic constructions, then it is perfectly understandable that the same individual can be a member of different worlds.

These answers to the TI-problem, anyway, depend on the stance one takes on the metaphysical nature of worlds. The appropriate transworld identity issue becomes evident when TI is phrased more neutrally in terms of ordinary Kripke semantics for quantified modal logic. In this phrasing, the fact that modal noneism faces no 'difficult questions about cross-world identity' also becomes evident. Let us see why.

Transworld identity can be felt as a problem from the viewpoint of ordinary modal semantics because Kripke frames notoriously involve varying domains (see Kripke [1963]). In a simple case, we have a structure $<W, R, f, v>$, where $W$ is the set of all (possible) worlds; $R$ is the usual binary accessibility relation (not to be confused with the ternary 'relevant' accessibility relation employed above within the presentation of modal noneist semantics); $v$ is the interpretation function. The element we are more interested in is $f$; this is the domain function, mapping members of $W$ to non-empty sets. Now the transworld identity claim can be reshaped as:

(TI) Some individual, $i$, is such that, for some worlds $w_{1}$ and $w_{2}, w_{1} \neq w_{2}$ and $i \in f\left(w_{1}\right)$ and $i \in f\left(w_{2}\right)$.

The intuitive reading is that, when $w \in W, f(w)$ is the domain of $w$, comprising the things that exist at $w$; and quantified formulas, when evaluated at $w$, have quantifiers ranging only over $f(w)$. However, sometimes also constant domain modal frames are phrased with a domain function - one just assumes that $f$ has constant values: for any two worlds $w_{1}$ and $w_{2}$ in the model, $f\left(w_{1}\right)=f\left(w_{2}\right)$ (see e.g. Fitting and Mendelsohn [1998], p. 102).

Now, from a Meinongian viewpoint the problem of this reading, of course, is that it conflates quantification and existence. Ordinary variable domain semantics try to capture the idea of contingent existence - the idea that things 'exist at' some, but not all worlds - by having objects included in the domain of some worlds and not of others. But modal noneism captures the intuition in a more straightforward way, by having things instantiate the (perfectly ordinary) property of existence at some, but not all worlds. Given the characterization of existence provided above, to exist at some world $w$ 
just is to have causal properties at $w$ and, perhaps, to be spatiotemporally available there. ${ }^{12}$

But even if we unburden the interpretation of 'is at' from any existential commitment in the TI-claim, the very idea of objects 'populating a world' as objects (whether or not they exist at that world) cannot match with the modal noneist semantics presented above. The reason is plain: it is not the case that objects 'are at' worlds. Objects are simply objects, that is, property bearers. What is 'at some world', 'not at some (other) world', is the having of properties by objects. The worlds apparatus aims at representing, as it were, the de re variation of properties had by objects. One had better avoid talk of objects 'being at', or 'being in' worlds altogether, and mirror this fact by having the domain of all objects directly represented in the set-theoretic frame, with no domain function at all. Even constant domain frames, when presented in terms of a function having worlds as arguments, could be taken as somewhat misleading: in interpreting the mathematical structure, one is encouraged to read 'is at' as something like 'is located within' - to think of worlds as things that have insides, like boxes or big containers. But - as van Inwagen has forcefully argued (in Van Inwagen [1986]) - worlds are not boxes, nor containers.

That the semantics above validates the Barcan schema,

$$
\diamond \Sigma x \alpha(x) \models \Sigma x \diamond \alpha(x)
$$

squares with these considerations. From the fact that it is possible that $b$ (who is actually sisterless) has a sister, it follows that something is such that it is possibly b's sister; and from the fact that it is possible that some fat man is in Quine's doorway, it follows that something is such that it is possibly a fat man in Quine's doorway. It is not the case that such things as things 'are at' the actual world, or 'are at' some other world(s). These are just things in the domain of the totality of objects; at some other world(s), they have the property of being b's sister, or fat men in Quine's doorway. And they need not exist at the actual world @ - they can well be nonexistent objects.

Modal noneism, therefore, respects the intuition that nothing is, in fact, sisterless $b$ 's sister at the actual world. But we can think about sisterless $b$ 's sister - call such an object ' $s$ ' - and we have, when $F=$ 'is $b$ 's sister', that @ $F^{+}$(C) Fs. What follows from this is only that the object so conceived is $b$ 's sister at the relevant worlds, that is, at the worlds $w$ such that $@ C w$ :

\footnotetext{
${ }^{12}$ It is a controversial issue whether variable domain Kripke semantics ultimately avoid commitment to mere possibilia and, therefore, to objects that do not exist (at @). I think this is not the case: there are Kripke models at which some objects in the domain of other worlds are not in the domain of the actual one. And the semantic metalanguage quantifies over them, even though they are out of reach for the object language quantifiers.
} 
$w \models^{+} F s$ (therefore, $w=^{+} \Sigma x F x$ ). In particular, when $w$ is a possible world, we may also grant that $s$ exists at $w$, if we think that being someone's sister is an existence-entailing property.

Does the fact that the transworld identity problem does not arise for modal noneism entail that the theory can avoid any form of haecceitistic de re representation of individuals by worlds? It seems not, and this can be made clear by considering the following objection to modal noneism, raised by Parsons [2006].

We have maintained that, according to the QCP, objects have the properties they are conceived as having at the worlds that realize the conception at issue. Now, let us consider Doyle's stories, and a world, $w_{1}$, at which the stories are true. At $w_{1}$, something has all the properties Holmes is characterized as having by the stories. This is Holmes. However, we can think of a situation in which you have all the properties ascribed to Holmes by Doyle's novels. Call $w_{2}$ the world at issue now (which may be a metaphysically possible one or not, give and take some intuitions one has about essential properties - an irrelevant point here). It seems that, at $w_{2}$, you are Holmes, and this, Parsons concludes, will not do.

The first thing to say about this problem is that it is not specific to Meinongianism, that is, to a theory that subscribes to the idea that some things do not exist. In fact, this is just a variant on the classic Chisholm [1967] Adam-Noah puzzle, which concerns actualists as much as Meinongians. The difficulty comes from the assumption that objects can be identified, as modal metaphysicians say, via a 'purely qualitative' account: we start with worlds, and if at some world something satisfies the Holmes characterization, it seems that that thing should be Holmes.

The solution for modal noneism consists in denying such assumption. The consequence of such a denial is a certain form of haecceitism: if $\alpha(x)$ is Holmes' characterization as provided by Doyle's stories, then a world $w_{1}$ can represent an individual, $i_{1}$, as characterized by $\alpha(x)$, whereas a world $w_{2}$ can represent a distinct individual, $i_{2}$, as characterized by $\alpha(x)$. There are worlds at which you satisfy the Holmes characterization. But Holmes is a nonexistent object (at @), whereas (perhaps luckily) you are not; so by the contraposed Leibniz's Law, you are not Holmes. There are also worlds at which Holmes, despite existing, does not satisfy the Holmes characterization - say, a world at which he is not a brilliant detective living in Baker Street, but a gardener in Birmingham. In Priest's words: "The identity of an object is not determined by its properties at any one world" (Priest [2005], p. 90). 


\section{Transworld Identification Is (Relatively) Not a Problem}

Unsurprisingly, the haecceitistic account to be endorsed by the noneist is broadly Kripkean; and this brings us directly to the issue of identification. The problem of transworld identification is due to Kaplan. It is, in fact, an epistemic one: how can we know whether we have a case of transworld identity? How are we to tell which object at another world is the same as an object at this world?

Scholars tend to consider transworld identity as a real issue (unless one is a counterpart theorist), and transworld identification as a pseudo-problem - which is probably due to the influence of Kripke [1980]. Other worlds are not something we glance at via the famous telescope. They are not the subject of empirical investigation: our access to other worlds is conceptual. We don't need to represent alternative situations in purely qualitative terms. "Generally, things aren't 'found out' about a counterfactual situation, they are stipulated" (Kripke [1980], p. 49) et cetera: the story is so well known that it hardly needs rehearsing (see also Plantinga [1974], p. 95; Chihara [1998]).

To some extent, the 'stipulation' solution works also for noneists. The deflationist answer to the question of how we identify Holmes at a given world may (perhaps with dismay) be that at any given world $w, x=$ Holmes if $x$ has the property of being precisely Holmes. The thought is that we can reason counterfactually on nonexistents as well as on existents, and if someone claims: 'Suppose that Holmes was killed in The Hound of the Baskervilles...', the question 'How do you know that it would be Holmes?' is spurious. Our task is not to find out which object in the other world is Holmes - this would be like "putting the cart before the horse." (Fitting and Mendelsohn [1998], p. 147).

However, it turns out that the Kripkean stipulation account does not solve all the questions raised for noneism by transworld considerations. In particular: stipulation cannot give infallible epistemic access to other worlds. ${ }^{13}$ To understand the issue, we have to enter the unstable realm of modal epistemology.

Call a priori knowledge whatever knowledge does not require some causal connection with the object known (there certainly are much more sophisticated characterizations around, but this one will be sufficient for our purposes). Meinongian nonexistent objects can be known, if at all, a priori. We assume here that a priori knowledge is in general possible and real - e.g.,

${ }^{13}$ This formulation of the point is due to Divers [2002], p. 273.

Australasian Journal of Logic (11:2) 2014, Article no. 1 
knowledge of sets and numbers. But one may claim that, even granting this, we have the following, specific problem about our allegedly a priori knowledge of Meinongian, nonexistent objects. Unlike sets and numbers, in modal noneism Pegasus and Holmes are supposed to be concrete, particular, nonabstract objects, that is, precisely the kind of things that, unlike sets and numbers, should be knowable only a posteriori. ${ }^{14}$

The noneist may reply by borrowing from Lewis [1986], p. 111 the following claim: the epistemic status (a priori/a posteriori) of our knowledge of object $x$ does not supervene on the metaphysical status of $x$ (abstract/concrete, existent/nonexistent), but on the modal status of the facts concerning $x$ (I will not discuss here whether Lewis' stance is vulnerable to objections from the availability of a priori contingent truths). The Qualified Comprehension Principle at the heart of modal noneism is supposed to explain why we know various things about nonexistent objects we have no causal acquaintance with - a knowledge which is, in this broad sense, a priori. As explained above, the core idea of a comprehension principle for objects is that objects have the properties they are characterized as having. This accounts for the manifest fact that, when we talk about flying horses, unicorns, Santa Claus, and Holmes, we usually know what we are talking about. ${ }^{15}$ Given a condition $\alpha(x)$, say, ' $x$ is a winged horse' we can talk of $\epsilon x \alpha(x)$, 'a winged horse', and be guaranteed that $\alpha(\epsilon x \alpha(x))$, that is, a winged horse is a horse with wings. But the noneist QCP for objects is a general metaphysical principle that accounts specifically for our modal knowledge of possible and impossible worlds. We can have abundant knowledge of modal facts by exploring the realm of possibilities (and impossibilities) completely a priori. What possibilities and impossibilities there are (that is, how the totality of worlds is) is not a variable subject matter. So we need no causal acquaintance with winged horses to know how one of them may look like: we know how a horse looks like, and we know how a pair of wings looks like, so we easily have the representation of a winged horse. ${ }^{16}$ What we cannot know a priori is what possibilitieswe @-inhabitants are: it takes causal acquaintance to establish whether something is a winged horse at @, that is, at this world.

\footnotetext{
${ }^{14}$ See Priest [2005], 136-7, on the concreteness of such Meinongian nonexistents as Holmes and Pegasus. Notice that this 'objection from concreteness' corresponds to the one raised by Skyrms (Skyrms [1976]) against Lewis' modal realism: after all, even though they exist, Lewisian possibilia share with nonexistent objects the feature that there is no causal or spatiotemporal relation with them.

${ }^{15}$ In Fitting and Mendelsohn's words: "Pegasus, Sherlock Holmes, Santa Claus. These do not appear to be utterly unreal. It is not as if one is faced with emptiness, a void: there is something on which to focus our attention and about which we can converse intelligently." (Fitting and Mendelsohn [1998], p. 176)

${ }^{16}$ See Lewis' Principle of Recombination, in Lewis [1986], p. 87-8.
} 
Let us now generalize these considerations. For any meaningful condition $\alpha(x)$, in the modal noneist theory some object - call it $o$ - can be conceived as satisfying it; so we have $@ \models^{+}$(C) $\alpha(o)$. One can take $\alpha(x)$ as the inconsistent condition ' $x$ is a round square': the noneist semantics above guarantees that, at some world $w, o$ is a round square: $w \models^{+} \alpha(o)$. What is not in our powers to 'stipulate' is that $w$ be a possible world and, a fortiori, that $w=@$. In general, we cannot stipulate at which worlds objects have the properties they are characterized as having - whether these are possible worlds, and whether they include the actual one. What one can fantasize about and what is the case in the real world, unfortunately, are at times severely different things. So we can extend to (the haecceitistic) modal noneism John Divers' claim that Kripkean 'stipulation' is not the panacea of modal metaphysics:

When I use the word 'Socrates' inside an explicitly worldly context, 'at w', or inside an implicitly worldly (modal or counterfactual) context (...) I do not thereby make it the case, nor do I come to know, that such a world is a possible world. It is this crucial point that underlies the complaint against (the claim that stipulation can give epistemic access to other worlds). It is one question how we know which objects are the objects of our de re modal thought and talk, and perhaps there stipulation has a legitimate role. It is another question altogether how we know what is modally true of those objects, and there stipulation has no legitimate role to play. (Divers [2002], p. 273)

\section{A Real Problem: Extensionally Indiscern- ible Nonexistents}

Besides the problem of having a principle producing a plenitude of nonexistent objects, Meinongian object theories notoriously face the problem of accounting for the identity of the (admitted) nonexistents. What is at issue, this time, has to do neither with epistemic subjects (how we can know and identify nonexistent objects), nor with problems of transworld identity; it is the question of what actually explains the identity of the object and accounts for it, which usually goes under the label of the 'criterion of identity' in the literature.

That Meinongian object theories may encounter difficulties in accounting for the identity of nonexistents is well known (besides the aforementioned notorious Quine [1948] - see also Lambert [1974]). Unsurprisingly, different kinds of Meinongianism embody in their principles of identity for objects 
the same basic notions they introduce for the respective characterization principles. Parsons' nuclear Meinongianism, for instance, has it that:

(NI) $x=y$ iff $x$ and $y$ have the same nuclear properties. (Parsons [1980], pp. 19 and 74)

Zalta's encoding Meinongianism has its principle of identity phrased as follows:

(EI) $x=y$ iff $x$ and $y$ encode the same properties. (Zalta [1983], pp. 13 and 33 )

What about modal noneism? The key feature of the noneist QCP, as we have seen, is its resorting to different worlds. Predictably, Priest formulates the corresponding principle of identity with respect to this notion, thereby embodying modality into it. An object is the object it is because it has the properties it has at the worlds where it has them:

(MI) $x=y$ iff $x$ and $y$ have the same properties at all worlds. ${ }^{17}$

A first qualm with MI comes from the thought that it involves a form of the Identity of Indiscernibles ${ }^{18}$ - a very controversial principle, as is well known. ${ }^{19}$ But even if the modal noneist provides an account of identity for nonexistents that takes identity as a primitive notion, more serious troubles lie in wait. Bluntly put, these depend on the fact that no such account, by definition, can involve any existence-entailing property. Given the idea of existence as (disposition to) causal interactivity, and/or spatiotemporal availability, favoured by noneists, no account of identity for nonexistents can involve such notions. But many philosophers accept only accounts of identity that involve causal and/or spatiotemporal features - at least for concrete objects: ${ }^{20}$ being in the same place at the same time, for instance. Therefore, no account of the identity of nonexistent objects is acceptable for these philosophers.

\footnotetext{
${ }^{17}$ Priest [2005], 88 and 114-5. Actually, Priest restricts the principle so as to exclude what he calls open worlds, and which correspond to our extensionally impossible worlds above. Furthermore, also properties including identity should be ruled out from the criterion, which otherwise gets trivialized (Ibid). These provisos, though, have no import for the current discussion.

18 "The identity of an object supervenes on the properties it has", says Priest [2005], p. 88. Later on, he claims that "to share some properties $(\ldots)$ is not sufficient for sharing all properties, and so being identical" (114).

${ }^{19}$ See Black [1952] for forceful and famous criticisms; see also Wiggins [2001], Ch. 1, Ladyman [2005].

${ }^{20}$ Abstract objects are a different story, of course: a Quinean extensionalist can accept sets on the ground that they have purely extensional identity conditions: $x$ and $y$ are the same set if they have the same members.
} 
The point can be made precise as follows. Call $x$ and $y$ extensionally indiscernible objects just in case they are distinct, but indiscernible with respect to all their non-modal properties, that is, properties not involving any reference to worlds other than @. Modal noneism is committed to extensionally indiscernible nonexistent objects: concrete, nonexistent things that are indiscernible if one looks at their 'extensional features', but are claimed to be distinct because they should be discernible at other worlds. Two nonexistent objects, $a$ and $b$, may have the same non-modal properties (say: at @, both are fictional characters, both are nonexistents, both are less famous than Immanuel Kant, etc.). This means that, to falsify ' $a=b$ ', one wants to claim that they differ in intensional and intentional features: one is thought about by someone but not the other; one is a detective at some other world $w$ but not the other; etc. To distinguish nonexistents, one sometimes can only (conceptually) look at other-worldly goings-on. ${ }^{21}$

But how can 'two' extensionally indiscernible nonexistent objects be claimed to be two, on the basis of alleged differences at other worlds? This is especially objectionable if one subscribes to the so-called Modal Supervenience (MS) thesis, to be found in various forms, for instance, in Jubien [1993], Levey [1997], Sider [1999], and Olson [2001]. In a slogan: 'No modal differences without actual differences'. To ground differences at the actual world on purely modal intuitions is 'to put the cart before the horse', for modal differences in their turn have to be grounded on actual differences.

The examples targeted in the literature are such allegedly coincident but distinct things as a statue, $s$, and the lump of clay, $c$, the statue is made of. Some ontologists claim that $s$ and $c$ are distinct, for $s$ could survive small parts replacement, whereas $c$ couldn't; $s$ didn't exist before the sculptor made it, whereas $c$ did; and so on (see Johnston [1992], Baker [1997], Thomson [1998], Fine [2000]). But, supporters of MS ask, how can $s$ and $c$ differ in their modal properties when they coincide in their actual properties? After all, they have the same shape, size, weight, colour, spatiotemporal location, etc. Where could modal differences come out from ${ }^{22}$ Generalizing: how could one resort to alleged modal and temporal differences, that is, properties whose

\footnotetext{
${ }^{21}$ See Priest [2005], 89 and 112-3 for examples of such intensional applications of the identity criterion.

${ }^{22}$ Here is Lewis in On the Plurality of Worlds: "we have one thing. What we have two of, besides names for it, are ways of representing. There is some kind of equivocation built into representation de re, and the equivocation shows up when we get conflicting answers. (...) It reeks of double counting to say that here we have a dishpan, and we also have a dishpan-shaped bit of plastic that is just where the dishpan is, weighs just what the dishpan weighs (why don't the two together weigh twice as much?), and so on. This multiplication of entities is absurd on its face" (Lewis [1986], p. 252).
} 
specification involves reference to other worlds or times, to settle the issue whether $s$ and $c$ are the same at @? How could one decide on identities and differences by (conceptually) peeking at other worlds, before identifying and differentiating things at this world? We cannot look at the modal features of things in order to establish identities and differences, before we have identified and distinguished such things: we cannot glimpse at their modal properties before we have ascertained whether they are the same or not. Questions concerning the modal features of objects presuppose that they have already been individuated, and such individuation has to be non-modal to begin with.

To be sure, also in this case the concern doesn't specifically affect nonexistents as such: it is orthogonal to the problem of Meinongian objects (we talk of an existing statue and an existing lump of clay, of course). However, if one subscribes to MS, this may rule out not only some existent objects, but (concrete) nonexistents as well; for the argument runs for the nonexistents $a$ and $b$ mentioned above, as it ran for the existents $s$ and $c$ : how could we discern the extensionally indiscernible $a$ and $b$ by resorting to differences at other worlds, before we have settled the problem of their identity at @?

A line of reply for the modal noneist may consist in simply adopting a deflationary attitude towards criteria of identity in general - again, just as many realists concerning (allegedly) existent but 'intensional' entities do (properties, propositions, universals, etc.). She may ask for independent arguments for countenancing only entities with universally acceptable criteria of identity; or even question the transparency of the very notion. ${ }^{23}$ She may try a tu quoque, by claiming (following Kripke [1978]) that we sometimes lack criteria of identity also for ordinary (and, to be sure, existing) objects; and (following French and Krause [1995]) even for the elementary particles of quantum physics. But whatever stance is taken by the modal noneist on these specific issues, we believe the discussion developed so far allows us to draw a more general moral.

\footnotetext{
${ }^{23}$ This route is taken by Parsons: " 'Principle of individuation' is technical jargon that needs to be explained. The trouble is, there simply is no explanation of what it means that would let a neutral observatory apply it to 'new' categories of (proposed) things. We have been given some examples (...) but no procedure has even been hinted at that would allow the examples to be generalized to new cases." (Parsons [1979a], p. 661)
} 


\section{Conclusion: Modal Noneism Is on the Mar- ket}

The most important lesson to learn from the issues addressed in this paper, I believe, is that (suspected or real) troubles for noneism aren't for the most part troubles that affect specifically its Meinongian ontology as such: they are orthogonal to the issue of nonexistence. Problems concerning criteria of identity, transworld identity and identification are to be dealt with by any theory involved with modalities, worlds semantics, and modal ontology, even when their proponents are hard-core actualists subscribing to the Quinean motto that to be is to be the value of a (bound) variable.

Besides, when addressing such problems, as we have seen, modal noneism performs fairly well overall. The theory can be tested with respect to how it organizes the linguistic, semantic and ontological phenomena it addresses, and how it provides a problem solving strategy for the recalcitrant data. When difficulties arise, different options are available to the modal noneist - some more palatable, some less. Sometimes a price has to be paid somewhere, whatever option is taken - as it happens, I believe, to any interesting philosophical view. This provides, albeit in a roundabout way, evidence for the idea that a priori dismissals of Meinongianism as a preposterous ontology are unmotivated. Gilbert Ryle once claimed that "Gegenstandstheorie $(\ldots)$ is dead, buried and not going to be resurrected." (Ryle [1973], p. 255). As often happens with people prematurely declaring the death of substantial philosophical positions, he was wrong and doomed to be refuted by subsequent developments.

\section{References}

Baker, L. (1997). Why constituton is not identity. Journal of Philosophy, 94:599-621.

Beall, J. and van Fraassen, B. (2003). Possibilities and Paradox. An Introduction to Modal and Many-Valued Logic. Oxford University Press, Oxford.

Black, M. (1952). The identity of indiscernibles. Mind, 61:152-164.

Bremer, M. (2005). An Introduction to Paraconsistent Logics. Peter Lang, Frankfurt a.M.

Chihara, C. (1998). The Worlds of Possibility. Oxford University Press, Oxford.

Australasian Journal of Logic (11:2) 2014, Article no. 1 
Chisholm, R. (1967). Identity through possible worlds: Some questions. Noûs, 1:1-8.

Divers, J. (2002). Possible Worlds. Routledge, London and New York.

Dunn, J. . (1986). Relevance logic and entailment. In Gabbay, D. and Guenthner, F., editors, Handbook of Philosophical Logic, volume III, pages 117-224. Kluwer, Dordrecht.

(ed.), L. M. (1979). The Possible and the Actual. Cornell University Press, Ithaca.

Findlay, J. (1963). Meinong's Theory of Objects and Values. Oxford University Press, New York.

Fine, K. (2000). A counter-example to locke's thesis. The Monist, 83:357361.

Fitting, M. and Mendelsohn, R. (1998). First-Order Modal Logic. Kluwer, Dordrecht.

French, S. and Krause, D. (1995). Vague identity and quantum nonindividuality. Analysis, 55:20-26.

Garson, J. . (1984). Quantification in modal logic. In Gabbay, D. and Guenthner, F., editors, Handbook of Philosophical Logic, volume II, pages 249-308. Kluwer, Dordrecht.

Griffin, N. (1998). Problems in item theory. (Paper read at 1998 meeting of the Australasian Association for Logic).

Jacquette, D. (1996). Meinongian Logic. The Semantics of Existence and Nonexistence. DeGruyter, Berlin and New York.

Johnston, M. (1992). Constitution is not identity. Mind, 101:89-105.

Jubien, M. (1993). Ontology, Modality and the Fallacy of Reference. Cambridge University Press, Cambridge.

Kripke, S. (1963). Semantical considerations on modal logic. Acta Philosophica Fennica, 16:83-94.

Kripke, S. (1978). Time and Identity. (manuscript).

Kripke, S. (1980). Naming and Necessity. Blackwell, Oxford. 
Ladyman, J. (2005). Mathematical structuralism and the identity of indiscernibles. Analysis, 65:218-221.

Lambert, K. (1974). Impossible objects. Inquiry, 17:303-314.

Levey, S. (1997). Coincidence and principles of composition. Analysis, 57:110 .

Lewis, D. (1986). On the Plurality of Worlds. Blackwell, Oxford.

Linsky, B. and Zalta, E. (1994). In defense of the simplest quantified modal logic. Philosophical Perspectives, 8:431-458.

Meinong, A. . (1969). $\dddot{i} \iota \frac{1}{2}$ ber gegenstandstheorie. In Haller, R. and Kindinger, R., editors, Alexius Meinong Gesamtausgabe. Akademische Druck und Verlagsanstalt, Graz.

Nolan, D. (1997). Impossible worlds: a modest approach. Notre Dame Journal of Formal Logic, 38:535-572.

Nolan, D. (1998). An uneasy marriage. (Paper read at the 1998 meeting of the Australasian Association of Philosophy).

Olson, E. (2001). Material coincidence and the indiscernibility problem. The Philosophical Quarterly, 51:337-355.

Parsons, T. (1979a). The methodology of nonexistence. Journal of Philosophy, 76:649-662.

Parsons, T. (1979b). Referring to nonexistent objects. Theory and Decision, 11:95-110.

Parsons, T. (1980). Nonexistent Objects. Yale University Press, New haven, Conn.

Parsons, T. (2006). Some remarks on graham priest's "towards non-being". (Paper presented at the Mid-West APA, Chicago).

Pasniczek, J. (1998). Beyond consistent and complete possible worlds. Logique et Analyse, 161:121-134.

Plantinga, A. (1974). The Nature of Necessity. Clarendon Press, Oxford.

Priest, G. (2001). An Introduction to Non-Classical Logic. Cambridge University Press, Cambridge.

Australasian Journal of Logic (11:2) 2014, Article no. 1 
Priest, G. (2005). Towards non-Being. The Logic and Metaphysics of Intentionality. Oxford University Press, Oxford.

Quine, W. (1948). On what there is. Review of Metaphysics, 48:21-38.

Rantala, V. (1982). Impossible world semantics and logical omniscience. Acta Philosophica Fennica, 35:106-115.

Rapaport, W. (1978). Meinongian theories and a russellian paradox. Nô̂s, 12:153-180.

Reicher, M. (2004). Nonexistent objects. The Stanford Encyclopedia of Philosophy.

Routley, R. (1980). Exploring Meinong's Jungle and Beyond. RSSS Australian National University, Canberra.

Routley, R. (1982). On what there is- not. Philosophy and Phenomenological Research, 43:151-177.

Routley, R. and Loparic, . (1978). Semantical analysis of arruda-da costa p systems and adjacent non-replacement relevant systems. Studia Logica, $37: 301-322$.

Russell, B. (1905a). On denoting. Mind, 14:479-493.

Russell, B. (1905b). Review of a. meinong "untersuchungen zur gegenstandstheorie und psychologie". Mind, 14:530-538.

Ryle, G. (1973). Intentionality-theory and the nature of thinking. Revue Internationale de Philosophie, 27:255-264.

Sider, T. (1999). Global supervenience and identity across times and worlds. Philosophy and Phenomenological Research, 59:913-937.

Skyrms, B. (1976). Possible worlds, physics and metaphysics. Philosophical Studies, 30:323-332.

Thomson, J. (1998). The statue and the clay. Nô̂s, 32:149-173.

Van Inwagen, P. . (1986). Plantinga on trans-world identity. In Tomberlin, J. and van Inwagen, P., editors, Alvin Plantinga, pages 101-120. Reidel, Dordrecht.

Vander Laan, D. (1997). The ontology of impossible worlds. Notre Dame Journal of Formal Logic, 38:597-620. 
Wiggins, D. (2001). Sameness and Substance Renewed. Cambridge University Press, Cambridge.

Wolterstorff, N. (1961). Referring and existing. The Philosophical Quarterly, 11:335-349.

Zalta, E. (1983). Abstract Objects. An Introduction to Axiomatic Metaphysics. Reidel, Dordrecht.

Zalta, E. (1997). A classically-based theory of impossible worlds. Notre Dame Journal of Formal Logic, 38:640-660.

Australasian Journal of Logic (11:2) 2014, Article no. 1 